\title{
Preface: Emerging trends in aquatic ecology II
}

\author{
Luigi Naselli-Flores $(\mathbb{D} \cdot$ Koen Martens $(\mathbb{D} \cdot$ - Diego Fontaneto $\mathbb{D} \cdot$ Sidinei Magela Thomaz $\mathbb{D}$
}

Published online: 19 July 2017

(C) Springer International Publishing AG 2017

\section{Introduction}

We are proud to present this Special Issue of Hydrobiologia, which celebrates the publication of the 800th Volume of the journal. It was nearly 70 years ago when the first issue circulated among aquatic biologists and our world has undergone significant changes since then. The most striking change is beyond any doubt related to technological developments, which have never been faster than in the past 70 years. Technology makes human life easier, but also requires the investment of higher amounts of energy. Such huge energy consumption, unfortunately still largely depending on fossil fuels,

Guest editors: Koen Martens, Sidinei M. Thomaz, Diego Fontaneto \& Luigi Naselli-Flores / Emerging Trends in Aquatic Ecology II

L. Naselli-Flores $(\bowtie)$

Department of Biological, Chemical and Pharmaceutical Sciences and Technologies - Section of Botany and Plant Ecology, University of Palermo, Palermo, Italy

e-mail: luigi.naselli@unipa.it

K. Martens

Royal Belgian Institute of Natural Sciences, OD Nature,

Freshwater Biology, Brussels, Belgium

e-mail: Koen.Martens@naturalsciences.be

\section{K. Martens}

Department of Biology, University of Ghent, Ghent, Belgium has enormous and cumulative impacts on our Planet, at present the only place in the universe where we can survive.

Survival of human beings as well as economic development still depend strongly on aquatic ecosystems, the target habitats of our journal's aims and scope. These ecosystems are particularly strongly exposed to human impacts as they ultimately receive all kinds of waste from our ever growing industrial and technological production (e.g. chemical contaminants and microplastics). They are also strongly influenced by the human-induced greenhouse gas emissions (e.g. warming and acidification), a by-product of our technological and industrial global growth, and by invasive species, the introduction of which is caused by increased international travel, be it for trade, tourism, or other. As a result, the integrity of aquatic ecosystems has been impaired in many places and

\author{
D. Fontaneto \\ Institute of Ecosystem Study, National Research Council \\ of Italy, Verbania Pallanza, Italy \\ e-mail: d.fontaneto@ise.cnr.it \\ S. M. Thomaz \\ Universidade Estadual de Maringá, DBI/PEA/Nupélia, \\ Maringá, PR, Brazil \\ e-mail: smthomaz@nupelia.uem.br
}


there is a serious risk that this may act as a boomerang on our future existence. We need to improve and to increase our knowledge on aquatic ecosystems' structure and functioning if we want to protect them and ourselves!

The editorial team of Hydrobiologia is committed to disseminate and archive knowledge on biological structure and functioning of aquatic ecosystems in the broadest way. By handling ca. 1,300 submitted manuscripts a year, Hydrobiologia editors are constantly screening for emerging trends in aquatic ecology worldwide (the journal received manuscripts from 101 different countries in 2015). This is the reason why the title of this Special Issue repeats that of the celebratory Volume 750 (Martens, 2015). Also, the present volume is a joint effort of the editors of Hydrobiologia and each paper has at least one editor as (co-)author. However, this time the focus is on freshwater ecosystems, the most endangered ecosystems of our Planet (WWF, 2016), especially considering the very limited percentage of water they contain (which sustain all Life on emerged lands) and the small amount of area they cover on Earth's surface.

As pointed out in the popular science book "A Short History of Nearly Everything" (Bryson, 2003), paradoxically, our knowledge about Life on our Planet is quite limited (especially as regard aquatic ecosystems which hold the bulk of Earth's biodiversity) compared with what we know about the Moon or other planets in our Solar System. There is therefore a strong need to increase our knowledge on freshwaters in order to understand how to use these resources without impairing the life they host, and on which we depend. To reach this goal we have (i) to improve our assessment on freshwater biological diversity, (ii) to understand how to preserve the structural integrity of these important ecosystems, (iii) to fully clarify both their functioning and the impacts of human actions on their functioning and (iv) to develop skills addressing their restoration. In order to achieve these tasks, Hydrobiologia editors are therefore again proposing a journey through some of the most imminent emerging trends in aquatic ecology research. This commitment will not reach an end with the present Special Issue and we hope that the "Emerging Trends in Aquatic Ecology" series can further grow and become a regular appointment with our readers.

\section{The present collection of "emerging trends" papers}

Investigations on freshwater ecosystem functioning still requires further research investments. A perfect example is offered by Forsberg et al. (2017), who analysed large-scale spatial and temporal variability of planktonic production and respiration in the Amazon floodplain. They found that these floodplain lakes emit more carbon dioxide than what is produced by their planktonic photosynthesis. These results indicate the existence of large and sustained inputs of nonphytoplankton organic carbon to these environments, which consequently increases the estimates of global aquatic $\mathrm{CO}_{2}$ outgassing. This has major implications for global climate policy.

In an attempt to understand how populations are distributed, four papers in the present volume analysed the spatial, environmental and/or historical factors that could explain the observed species distribution patterns in a variety of environments. All of these studies focussed on passively dispersed microalgae and zooplankton. In particular, Zorzal-Almeida et al. (2017) analysed the relative contribution of environmental heterogeneity, spatial extent and productivity in determining the $\beta$-diversity of benthic diatoms in tropical reservoirs, whereas phytoplankton diversity patterns were studied in two sets of subtropical reservoirs in South-America and Asia (Hu et al., 2017; Wojciechowski et al., 2017). Marrone et al. (2017) reviewed the diversity patterns of calanoid copepods in the different limnoregions of the West Palaearctic and performed a biogeographical analysis revealing two different post-glacial colonization patterns in the Western and Eastern part of the Mediterranean Basin, most likely depending on the different orientation of the main mountain ranges in that region. Generally, these studies reveal the existence of complex patterns depending on historical, spatial/ environmental and biological factors, for example historical climatic events, different dispersal abilities of organisms, distances and structural heterogeneity among ecosystems, environmental filters acting within the ecosystems themselves and others. These four studies challenge the view that compositional variation of microorganism communities totally depend on environmental selection operating locally, the latter being just the end of a complex series of processes which depend on microorganism dispersal abilities over time and space (for more details see Fontaneto, 
2011 and Incagnone et al., 2015). These results can also have practical applications when management plans are developed in a given region, since aquatic ecosystems cannot and should not be considered as "black-boxes", but as interlinked networks that, in some cases, can cover very wide areas.

Spatial heterogeneity is relevant also when the structure of assemblages is studied at narrow scales. As shown by Mendes et al. (2017), inter-habitat spatial heterogeneity has a greater effect on the structure of aquatic invertebrate communities and guilds associated with leaf-patches than that recorded in adjacent catchments located in the Atlantic Forest. Analogously, Jeppesen et al. (2017) investigated the structure of invertebrates in 87 Greenland lakes, some with and some without fish. Their results show that the cascading effect of fish on the structure of invertebrates is not univocally determined, but depends in turns on the complex trophic relationships that exist amongst members of the fish communities and guilds present in the lake.

One of the limits encountered in analysing diversity patterns is represented by the confidence with which we are able to assign a specific name to studied organisms. Schön et al. (2017), offered a detailed investigation on cryptic diversity and speciation patterns in Cytherissa, a genus of ostracod crustaceans almost exclusively represented by endemic species in the Siberian Lake Baikal. Their results clearly show that the actual biodiversity of endemic Cytherissa in Lake Baikal is much higher than previously thought and open the way to deeper investigations on speciation models. The availability of molecular tools has greatly increased the number of known species during the last decades, revealing an unexpectedly high cryptic diversity, especially in freshwaters, which has remained largely unexplored by traditional, morphology-based taxonomy.

As shown by Larson et al. (2017) and by Monchamp et al. (2017), molecular tools are also extremely useful to identify DNA fragments from the sediments (environmental DNA or eDNA), allowing to provide support to present and retrospective analyses on community dynamics or to reconstruct the invasion patterns of alien species, respectively. These results strongly support the possibility to use eDNA to detect elusive species, to screen large areas to monitor biological invasions in aquatic ecosystems, or to unveil how the different compartments of food-webs co-vary in changing environments.

The importance of sediments was also considered, from two different perspectives, in the papers by Slemmons et al. (2017) and Amalfitano et al. (2017). The first article examined the sedimentary diatom profiles in the US Rocky Mountains to investigate when glacially fed lakes started receiving nitrogen subsidies. Actually, this lake typology has much higher nitrate concentrations, a lower species richness over time and a greater species turnover compared to snow-fed lakes. The effect of glaciers on the biogeochemical cycles of the lakes they feed, which in some cases dates back to several centuries ago, represent an important historical factor that has to be considered when the distribution patterns of species in highmountain lakes are investigated.

The paper by Amalfitano et al. (2017) deals with the limitation of distinguishing settling authigenic particles from resuspended sediments as a crucial prerequisite to assess the ecological relevance of particulate matter in aquatic systems. Based on findings about specific physiological traits and bacterial community structure, the authors propose to investigate the particle-associated microorganisms to distinguish resuspended sediments from other suspended solids. Developing such a method will have important implications when assessing the origin and fate of chemical and microbiological contamination in freshwaters with special reference to antibiotics and antibiotic-resistant strains.

Contamination of freshwater can have negative effects on the services provided by freshwater ecosystems. As shown by Gal \& Zohary (2017), sustaining the effectiveness of these services over time is not a trivial task. These authors modified an existing water quality index and developed a specific "Lake Kinneret Ecosystem Sustainability Index". While the modified index is specific to Lake Kinneret, the underlying assumptions, variables, and the form of application are generic and could be used to develop similar indices for other freshwater lakes around the world. This is an important contribution, because whereas biotic indices for lotic aquatic habitats abound, similar indices for lentic habitats have generally been elusive.

Last but not least, invasive species may have significant ecological and economic effects on aquatic ecosystems. Environmental Agencies use a variety of chemical, physical and biological methods to control 
them and to limit invasions. An experimental approach to test the effectiveness of biological control, through stocking milfoil weevils, for reducing the biomass of the Eurasian watermilfoil in North American lakes, was adopted by Havel et al. (2017). The paper offers a detailed account of the costs and benefits deriving from adopting such a control in natural environments and highlights the risks deriving from applying this method without carefully considering all the environmental conditions that may influence the efficacy of stocking for biological controls.

\section{Conclusions}

We wish to thank all Hydrobiologia editors and their co-authors, for producing the papers in this Special Issue, and all the referees that offered their time to ensure extensive reviews of these manuscripts. We are deeply indebted to the staff of Springer who assisted us in all the necessary steps and contributed to make the production of the final volume smoother, in spite of the rather severe time pressures.

The issues discussed in the present volume analyse some emerging trends in aquatic ecology, hoping to contribute towards an improved understanding of freshwater ecosystem functioning. Together with the authors who contributed to these articles, we sincerely hope our readership will enjoy these papers, which aim to be "sturdy houses of brick" (Kaelin, 2017). We therefore have the ambition that the science contained in the present volume will provoke new ideas and new research programs worldwide amongst our readership and beyond.

\section{References}

Amalfitano, S., G. Corno, E. Eckert, S. Fazi, S. Ninio, C. Callieri, H.-P. Grossart \& W. Eckert, 2017. Tracing particulate matter and associated microorganisms in freshwaters. Hydrobiologia. doi:10.1007/s10750-017-3260-x.

Bryson, B., 2003. A Short History of Nearly Everything. Broadway Books, New York.

Fontaneto, D. (ed.), 2011. Biogeography of Microscopic Organisms. Is Everything Small Everywhere? Cambridge University Press, Cambridge.

Forsberg, B. R., J. M. Melack, J. E. Richey \& T. P. Pimentel, 2017. Regional and seasonal variability in planktonic photosynthesis and planktonic community respiration in
Amazon floodplain lakes. Hydrobiologia. doi:10.1007/ s10750-017-3222-3.

Gal, G. \& T. Zohary, 2017. Development and application of a sustainability index for a lake ecosystem. Hydrobiologia. doi:10.1007/s10750-017-3269-1.

Havel, J. E., S. E. Knight \& K. A. Maxson, 2017. A field test on the effectiveness of milfoil weevil for controlling Eurasian watermilfoil in Wisconsin lakes. Hydrobiologia. doi:10. 1007/s10750-017-3142-2.

Hu, R., X. Duan, L. Peng, B.-P. Han \& L. Naselli-Flores, 2017. Phytoplankton assemblages in a complex system of interconnected reservoirs: the role of water transport in dispersal. Hydrobiologia. doi:10.1007/s10750-017-3146-y.

Incagnone, G., F. Marrone, R. Barone, L. Robba \& L. NaselliFlores, 2015. How do freshwater organisms cross the "dry ocean"? A review on passive dispersal and colonization processes with a special focus on temporary ponds. Hydrobiologia 750: 103-123.

Jeppesen, E., T. L. Lauridsen, K. S. Christoffersen, F. Landkildehus, P. Geertz-Hansen, S. Lildal Amsinck, M. Søndergaard, T. A. Davidson \& F. Rigét, 2017. The structuring role of fish in Greenland lakes: an overview based on contemporary and paleoecological studies of lakes from the low and the high Arctic. Hydrobiologia. doi:10.1007/s10750-017-3279-z

Kaelin Jr., W. G., 2017. Publish houses of brick, not mansions of straw. Nature 545: 387.

Larson, E. R., M. A. Renshaw, C. A. Gantz, J. Umek, S. Chandra, D. M. Lodge \& S. P. Egan, 2017. Environmental DNA (eDNA) detects the invasive crayfishes Orconectes rusticus and Pacifastacus leniusculus in large lakes of North America. Hydrobiologia. doi:10.1007/s10750-0173210-7.

Marrone, F., G. Alfonso, L. Naselli-Flores \& F. Stoch, 2017. Diversity patterns and biogeography of Diaptomidae (Copepoda, Calanoida) in the Western Palearctic. Hydrobiologia. doi:10.1007/s10750-017-3216-1.

Martens, K., 2015. Preface: emerging trends in aquatic ecology. Hydrobiologia 750: 1-4.

Mendes, F., W. P. Kiffer \& M. S. Moretti, 2017. Structural and functional composition of invertebrate communities associated with leaf patches in forest streams: a comparison between mesohabitats and catchments. Hydrobiologia. doi:10.1007/s10750-017-3249-5.

Monchamp, M.-E., I. Enache, P. Turko, F. Pomati, G. Rîşnoveanu \& P. Spaak, 2017. Sedimentary and egg-bank DNA from 3 European lakes reveal concurrent changes in the composition and diversity of cyanobacterial and Daphnia communities. Hydrobiologia. doi:10.1007/ s10750-017-3247-7.

Schön, I., V. Pieri, D. Yu Sherbakov \& K. Martens, 2017. Cryptic diversity and speciation in endemic Cytherissa (Ostracoda, Crustacea) from Lake Baikal. Hydrobiologia. doi:10.1007/s10750-017-3259-3.

Slemmons, K. E. H., M. L. Rodgers, J. R. Stone \& J. E. Saros, 2017. Nitrogen subsidies in glacial meltwaters have altered planktonic diatom communities in lakes of the US Rocky Mountains for at least a century. Hydrobiologia. doi:10. 1007/s10750-017-3187-2.

Wojciechowski, J., J. Heino, L. M. Bini \& A. A. Padial, 2017. The strength of species sorting of phytoplankton 
communities is temporally variable in subtropical reservoirs. Hydrobiologia. doi:10.1007/s10750-017-3245-9.

WWF, 2016. Living Planet Report 2016. Risk and Resilience in a New Era. WWF International, Gland.
Zorzal-Almeida, S., L. M. Bini \& D. Campos Bicudo, 2017. Beta diversity of diatoms is driven by environmental heterogeneity, spatial extent and productivity. Hydrobiologia. doi:10.1007/s10750-017-3117-3. 